\title{
PERANAN ZAKAT, INFAK DAN SEDEKAH (ZIS) \\ DALAM UPAYA MENINGKATKAN PEREKONOMIAN MASYARAKAT \\ KOTA METRO \\ (Studi Pada Lazisnu Kota Metro)
}

\author{
Ani Mardiantari \\ Institut Agama Islam Ma'arif NU (IAIMNU) Metro Lampung \\ anisujarwo.am@gmail.com
}

\begin{abstract}
Zakat, infaq and almsgiving is one of the worship in Islam to seek pleasure from Allah SWT. In Islam besides worshiping zakat, infaq and almsgiving are also effective solutions for poverty alleviation. Therefore a zakat, infaq and alms management body is needed which has a good management mechanism and has an optimal role in efforts to improve the economy in the community. LAZISNU Metro City was formed in order to maximize the management of zakat and maximize the increase in the economy of the community in Metro City. The results of this study indicate that the zakat management mechanism that exists in LAZISNU Metro City is quite good, but there are still some parts that are not maximal due to the obstacles faced. The role of zakat, infaq and almsgiving in an effort to improve the economy of the community in Metro City runs in the form of consumptive assistance and productive assistance. The implementation is carried out based on Islamic law and the Law. Therefore LAZISNU Metro City needs to continue to evaluate in order to achieve a maximum role in an effort to improve the economy of the community in Metro City.
\end{abstract}

Keywords: Role, Alms of Infaq Alms, improve the economy

\begin{abstract}
Abstrak Zakat, infak dan sedekah merupakan salah satu ibadah dalam Islam untuk mencari keridhaan dari Allh swt. Dalam Islam selain sebagai ibadah zakat, infak dan sedekah juga merupakan solusi efektif untuk penanggulangan kemiskinan. Oleh karena itu diperlukan sebuah badan pengelolaan zakat, infak dan sedekah yang memiliki mekanisme pengelolaan yang baik serta memiliki peran yang optimal dalam upaya peningkatan perekonomian pada masyarakat. LAZISNU Kota Metro dibentuk agar bisa memaksimalkan pengelolaan zakat dan memaksimalkan peningkatan perekonomian masyarakat di Kota Metro. Hasil penelitian ini menunjukkan bahwa mekanisme pengelolaan zakat yang ada LAZISNU Kota Metro sudah cukup baik, namun masih terdapat beberapa bagian yang kurang maksimal disebabkan oleh kendala yang dihadapi. Adapun peranan zakat, infak dan sedekah dalam upaya meningkatkan perekonomian masyarakat di Kota Metro berjalan dalam bentuk bantuan konsumtif dan bantuan produktif. Pelaksanaannya dilakukan berdasarkan syariat Islam dan Undang-undang. Oleh
\end{abstract}


karena itu LAZISNU Kota Metro perlu terus melakukan evaluasi guna tercapainya peran yang maksimal dalam upaya meningkatkan perekonomian masyarakat di Kota Metro.

Kata Kunci: Peranan, Zakat Infak Sedekah, meningkatkan perekonomian

\section{PENDAHULUAN}

Kemiskinan merupakan salah satu permasalahan besar yang ada di Indonesia, bahkan di tahun 1997 Indonesia pernah mengalami krisis moneter yang hal itu mengakibatkan angka kemiskinan di Indonesia meningkat. Hal ini merupakan salah satu dampak dari sekian banyaknya usaha kegiatan ekonomi yang terhenti sehingga mengakibatkan angka pengangguran meningkat.

Dalam agama Islam salah satu instrumen yang menjadi sumber pendapatan adalah zakat, infak dan sedekah (ZIS). ZIS sebagai salah satu cara menanggulangi kemiskinan yaitu dengan adanya dukungan dari orang yang mampu mengeluarkan hartanya untuk diberikan kepada yang membutuhkan. Akan tetapi, selama ini zakat masih dilihat sebelah mata bagi sebagian orang padahal zakat mempunyai peranan yang sangat penting bagi upaya penurunan tingkat kemiskinan di Indonesia.

Zakat tidak mempunyai hubungan timbal balik apapun kecuali hanya mengharap ridho Allah SWT. Zakat merupakan suatu kewajiban yang sangat ditekankan kepada hamba-Nya untuk menunaikannya, kewajiban berzakat ini sama dengan kewajiban mendirikan sholat.

Salah satu fungsi utama daripada zakat adalah untuk meningkatkan kesejahteraan masyarakat, zakat dibayarkan oleh mereka yang mampu dan mempunyai hasil yang sudah sesuai dengan nisabnya yang telah ditentukan oleh syariat Islam. Zakat ini umumnya penyalurannya dilakukan melalui badan yang disebut dengan amil zakat dan disalurkan untuk orang-orang yang berhak menerimanya (mustahiq).

Pada dasarnya zakat itu dikeluarkan oleh orang-orang yang mempunyai kewajiban untuk berzakat yang disebut dengan muzakki. Zakat yang sudah terkumpul lalu didistribusikan kepada para golongan yang berhak menerima 
zakat. Para muzakki membayarkan zakatnya ada yang dibayarkan sendiri kepada si penerima zakat namun ada pula yang melalui perantara yang biasa disebut dengan amil.

Pengelolaan zakat di Indonesia sekarang ini sudah menuju ke arah yang lebih baik. Pendistribusian zakat merupakan salah satu faktor yang dijadikan tolak ukur bagi umat Islam untuk memilih lembaga yang dipercaya dalam pengelolaan zakat. Keberhasilan dari pengelolaan zakat sangat bergantung pada proses pendistribusian zakat tersebut.

Pengelolaan distribusi zakat yang diterapkan di Indonesia terdapat dua macam kategori yaitu distribusi secara konsumtif dan produktif. Secara konsumtif bisa diartikan bahwasannya zakat langsung diberikan pada mustahik untuk memenuhi kebutuhan hidupnya yang mungkin hanya cukup untuk satu dua hari saja. Sedangkan secara tidak langsung zakat didistribusikan secara produktif yang ini artinya bahwa zakat yang disalurkan oleh amil zakat itu tidak bisa dinikmati secara langsung hasilnya oleh para mustahiq, pendistribusian zakat dengan model ini biasanya dalam bentuk usaha yang pengelolanya bisa dari pengelola zakat maupun dari para mustahiq hasil yang diperoleh dari usaha tersebutlah yang dikonsumsi oleh para mustahiq.

Pengelolaan zakat secara produktif yang diberikan kepada mustahiq akan berperan dalam peningkatan perekonomian apabila hal ini didayagunakan, karena pada dasarnya zakat secara produktif pasti mempunyai perencanaan dan pelaksanaan yang cermat karena biasanya dalam hal ini akan dikaji tentang penyebab kemiskinan, ketiadaan modal dan lain sebagainya oleh sebab itu zakat yang bersifat produktif perlu lebih dikembangkan lagi.

Peranan zakat untuk meningkatkan perekonomian rakyat sebenarnya sangat besar sekali, akan tetapi hingga kini masih banyak umat muslim yang belum menyadari pentingnya membayar zakat. Banyak faktor yang dijadikan sebagai penyebab diantaranya adalah: Pertama, tingkat kepercayaan masyarakat yang masih rendah kepada lembaga-lembaga pengelola zakat, akibatnya banyak masyarakat yang mengeluarkan zakatnya langsung kepada mustahik. Kedua, 
masih banyak kaum muslimin yang belum mengerti cara menghitung zakat dan kepada siapa zakatnya dipercayakan untuk disalurkan.

Peran lembaga amil zakat sangat penting sekali, oleh sebab itu LAZISNU Kota Metro sebagai lambaga pengelolaan dan pendistribusian zakat, infak dan sedekah harus bisa secara optimal mendampingi dan memberikan pengarahan serta pelatihan agar zakat yang diberikan untuk modal usaha tersebut benar-benar dikelola secara baik dan bertanggung jawab sehingga penerima zakat tersebut memperoleh pendapatan yang bisa meningkatkan perekonomian. Penelitian ini akan mengungkapkan Bagaimanakah mekanisme pengelolaan zakat pada LAZISNU Kota Metro? Dan Bagaimanakah peranan LAZISNU Kota Metro dalam upaya meningkatkan perekonomian masyarakat?

\section{PEMBAHASAN}

\section{A. Sejarah Berdirinya LAZISNU Kota Metro}

LAZISNU Kota Metro adalah lembaga tingkat zakat nasional yang berkhidmat dalam pemberdayaan masyarakat melalui pendayagunaan secara produktif yang diperoleh baik dari perorangan, lembaga perusahaan dan instansi lainnya.

LAZISNU Kota Metro ini didirikan oleh PCNU Kota Metro pada tahun 2013 yang ditandai dengan penandatanganan oleh Pengurus Cabang Nahdlatul Ulama Kota Metro yaitu KH. Zainal Abidin, Kyai Zamroni Ali, Drs. KH. Ali Qomaruddin, M.M dan Drs. Supardi dan selanjutnya dikukuhkan oleh Menteri Agama Republik Indonesia sebagai lembaga Amil Zakat Nasional melalui SK No. 65 Tahun 2005 pada masa khidmat 2014 - 2019. ${ }^{1}$

Sehingga pada tahun 2014 untuk pertama kalinya didirikan LAZISNU Kota Metro yang diketuai oleh Bapak Dr. Subandi M.M melakukan Konfercab (konferensi Cabang). Seiring berkembangnya waktu dan kemudian terstruktur melalui manajemen - manajemen yang dilakukan sampai ke tingkat MWC dan UPZ - UPZ setempat. 
Program LAZISNU Kota Metro meliputi NUcare, NUpreneur, NUskill,dan NUsmart. Untuk para muzaki yang ingin menyalurkan zakatnya, LAZISNU Kota Metro memberikan beberapa kemudahan yaitu: ${ }^{2}$

a. Zakat Secara Langsung

Menggunakan metode secara langsung yaitu dengan cara datang langsung ke kantor LAZISNU Kota Metro yang terletak di Gedung PC NU Kota Metro Jl. Soekarno Hatta No 73 Mulyojati Metro Barat Kota Metro Lampung 34121

b. Mentransfer Melalui Rekening Zakat atas nama LAZISNU Kota Metro:

1. BRI Zakat

2. BRI Infaq dan Shadaqah

3. BMT Artha Buana

c. Sistem Jemput Zakat (Door to Door $)^{3}$

\section{B. Mekanisme Pengelolaan Dana ZIS oleh LAZISNU Kota Metro}

Mekanisme pengelolaan zakat infak dan sedekah yang dilakukan oleh LAZISNU Kota Metro meliputi:

1) Analisis Perencanaan

Perencanaan adalah sejumlah kegiatan yang ditentukan sebelumnya untuk dilaksanakan pada suatu periode tertentu dalam rangka mencapai tujuan yang ditetapkan. ${ }^{4}$

Pada tahun 2017 fokus perencanaan yang akan dilakukan oleh LAZISNU Kota Metro tertuju pada pembenahan manajemen dengan tujuan peningkatan grafik pertumbuhan ekonomi dan upaya membantu sesama masyarakat Nahdiyah atau masyarakat yang membutuhkan dari tahun ke tahun ${ }^{5}$

2) Analisis Pengorganisasian

Pengorganisasian adalah pengaturan kerja bersama sumber daya keuangan, fisik dan manusia dalam organisasi. Pengorganisasian merupakan penyusunan struktur organisasi sesuai dengan tujuan organisasi, SDM dan lingkungan. ${ }^{6}$ 
Guna terwujudnya suatu organisasi atau lembaga yang sehat, maka LAZISNU Kota Metro merumuskan bentuk pengorganisasian yang baik yaitu: (1) adanya struktur organisasi, (2) adanya pembagian tugas yang sesuai dengan keahlian, (3) adanya koordinasi dan wewenang.

3) Analisa pelaksanaan

Pada tahap pelaksanaan LAZISNU Kota Metro menekankan pada dua analisa yaitu: (1) Analisis pelaksanaan penghimpunan dana ZIS dilakukan dengan memuat program, menyentuh hati para donatur, bekerjasama dengan perusahaan. (2) Strategi penggalangan dana, dalam hal ini pihak LAZISNU Kota Metro masih terus mengalami perkembangan, ide-ide yang potensial masih terus dicari untuk lebih mengembangkan program ini, karena program ini masih merupakan program yang baru yang belum banyak masyarakat ketahui. Salah satu strategi penggalangan dana yang baru berdiri dan berlangsung pada tahun 2017 ini adalah program 1000 berkah yang bekerjasama dengan IAIM NU Metro Lampung. ${ }^{7}$

Analisa penetapan pendistribusian dan pendayagunaan dana zakat, infak, dan sedekah dilaksanakan berdasarkan hasil musyawarah antara pengurus harian LAZISNU Kota Metro.

Lebih lanjut ketua LAZISNU Kota Metro Bapak Subandi mengutarakan bahwa:

"Supaya efektif pendistribusian zakat, infak dan sedekah ini kami benarbenar selektif. Makanya kita bikin aturan dan persyaratan supaya zakat yang didistribusikan itu tepat sasaran. Mereka yang berhak mendapat zakat, infak dan sedekah dari tiap-tiap daerah di Kota Metro datanya kita dapatkan dari pengurus MWC masing-maisng kelurahan di Kota Metro. Data ini kemudian kami kaji baru kemudian ketika memenuhi syarat kami distribusikan". ${ }^{8}$

Pendistribusian zakat yang telah direncanakan oleh NU Care LAZISNU Kota Metro yaitu terkait dengan kegiatan (1) Program bantuan pendidikan, (2) Program bantuan kesehatan, (3) Program bantuan pemberdayaan ekonomi, (4) Program bantuan tanggap bencana. ${ }^{9}$

4) Analisa Pengawasan 
Bentuk pengawasan yang ada di LAZISNU Kota Metro salah satunya yaitu dengan pengumpulan hasil pendistribusian atau laporan dari masing - masing MWC setempat dari seluruh bagian di Kota Metro baik secara bulanan maupun periodik melalui sistem informasi yang relevan. Pengawasan juga melibatkan perangkat desa setempat dengan mengadakan kegiatan yasin dan tahlil juga kegiatan lailatul ijtima'. ${ }^{10}$

Dalam Manajemen Pengawasan yang dilakukan oleh LAZISNU Kota Metro sebenarnya sudah cukup baik. Tapi dalam hal evaluasi mungkin perlu dilakukan laporan secara berkala bisa harian, bulanan bahkan tahunan, hal ini agar pengawasan dan pengendalian yang dilakukan oleh LAZISNU Kota Metro bisa berjalan secara efektif dan efisien.

\section{Peranan ZIS Terhadap Kesejahteraan Muzakki}

Zakat wajib didistribusikan kepada mustahiq sesuai dengan syariat Islam dan berdasarkan skala prioritas dengan memperhatikan prinsip pemerataan, keadilan dan kewajiban. Begitu pula pada LAZISNU Kota Metro dalam menjalankan fungsinya telah menyusun beberapa program kerja sebagai realisasi amanah dari para muzakki. Program-program tersebut disusun berdasarkan pengkajian dan penyesuaian dengan bentuk dana yang masuk seperti zakat, infak dan sedekah.

Pemilahan yang dilakukan LAZISNU Kota Metro pada jenis-jenis dana yang masuk bertujuan untuk mengantisipasi tercampurnya dana zakat dengan dana lainnya. Sebab dana zakat memiliki peruntukan khusus dalam pendistribuasiannya.

Dalam upaya peningkatan kesejahteraan masyarakat LAZISNU Kota Metro telah mempunyai perencanaan yang baik dalam menjalankan fungsinya dengan mengupayakan penyaluran zakat infak dan sedekah dalam mengentaskan kemiskinan sesuai dengan peruntukannya.

Pengelolaan dan penyaluran dana zakat, infak dan sedekah pada LAZISNU Kota Metro direalisasikan dengan dua pengembangan yaitu:

1. Pengembangan Ekonomi Dengan Bantuan Konsumtif 
Bantuan konsumtif adalah bantuan langsung yang diberikan kepada para masyarakat pra sejahtera (mustahiq) yang berhak menerimanya (bantuan kaum dhuafa/fakir miskin).

Bantuan konsumtif yang diberikan LAZISNU Kota Metro dengan nominal tertentu memiliki manfaat yang besar. Dengan penyaluran ini mustahiq dapat menggunakannya untuk memenuhi kebutuhan hidup dan ini dapat mengurangi persoalan ekonomi seperti kemiskinan. Diantara realisasi penyaluran bantuan konsumtif digunakan untuk biaya pendidikan dengan rincian sebagai berikut:

\begin{tabular}{|c|c|c|c|c|c|}
\hline \multirow{2}{*}{ Program } & \multirow{2}{*}{$\begin{array}{c}\text { Pelaksanaan } \\
\text { Program }\end{array}$} & \multirow{2}{*}{ Waktu } & \multicolumn{3}{|c|}{ Rincian Biaya } \\
\hline & & & Volume & Satuan & Jumlah \\
\hline \multirow{3}{*}{$\begin{array}{c}\text { NU } \\
\text { Smart: }\end{array}$} & \multirow{3}{*}{$\begin{array}{c}\text { Pemberian } \\
\text { beasiswa } \\
\text { miskin untuk } \\
\text { pendidikan }\end{array}$} & $\begin{array}{l}\text { September } \\
2014\end{array}$ & $\begin{array}{l}6 \text { anak } \\
\text { SMP } \\
6 \text { anak } \\
\text { SMK }\end{array}$ & $\begin{array}{l}300.000 \\
300.000\end{array}$ & 1.800 .000 \\
\hline & & $\begin{array}{l}\text { Oktober } \\
2015\end{array}$ & $\begin{array}{l}6 \text { anak } \\
\text { SMP } \\
6 \text { anak } \\
\text { SMK }\end{array}$ & $\begin{array}{l}300.000 \\
300.000\end{array}$ & 1.800 .000 \\
\hline & & $\begin{array}{l}\text { Oktober } \\
2016\end{array}$ & $\begin{array}{l}6 \text { anak } \\
\text { MI } \\
6 \text { anak } \\
\text { SMP } \\
6 \text { anak } \\
\text { SMA/S } \\
\text { MK }\end{array}$ & $\begin{array}{l}300.000 \\
500.000 \\
750.000\end{array}$ & $\begin{array}{l}1.800 .000 \\
3.000 .000 \\
4.500 .000\end{array}$ \\
\hline
\end{tabular}

Ketua LAZISNU Kota Metro, Bapak Subandi mengutarakan bahwa:

"Bantuan konsumtif ini meskipun sifatnya cepat habis namun harus tetap kita berikan. Sebab ada kebutuhan-kebutuhan mustahiq yang memang mendesak dan mereka berhak mendapatkannya. ${ }^{11}$ 
Dari keterangan di atas terlihat bahwa LAZISNU Kota Metro juga memahami bahwa penyaluran zakat yang bersifat konsumtif tetap harus terlaksana, meskipun terkesan bagi sebagian orang kurang menanggulangi kemiskinan.

2. Pengembangan Ekonomi Dengan Bantuan Produktif

LAZISNU Kota Metro dalam menjalankan fungsi penganggulangan kemiskinan dengan bantuan produktif telah memiliki program pengembangan ekonomi bagi mustahik yaitu dengan bantuan usaha bergulir.

Hingga pertengahan tahun 2017, LAZISNU Kota Metro telah memiliki 22 ranting binaan dalam bantuan modal usaha bergulir yaitu berupa pemeliharaan kambing. Dengan rincian 4 orang binaan di MWC Metro Timur, 4 orang binaan di MWC Metro Utara, 4 orang binaan di MWC Metro Pusat, 4 orang binaan di MWC Metro Selatan dan 6 orang binaan di MWC Metro Barat.

Ketua LAZISNU Kota Metro, Bapak Subandi mengutarakan bahwa: "Bantuan produktif kita berikan kepada mustahiq yang sebelumnya sudah kita kasih pengarahan. Bantuan berupa kambing bergulir ini syaratnya sangat mudah, oleh sebab itu diharapkan kepada si penerima kambing ini agar bisa memelihara bantuan tersebut, dan nantinya si kambing sudah beranak maka anak pertama ini harus dikembalikan kepada LAZISNU Kota Metro untuk digulirkan kembali kepada penerima bantuan selanjutnya dan untuk induk dan anak kambing seterusnya menjadi hak milik pemeliharanya". ${ }^{12}$

Realisasi program penyaluran dan pendayagunaan dana zakat, infak dan sedekah produktif dapat dilihat dalam tabel di bawah ini:

\begin{tabular}{|c|c|c|c|c|c|}
\hline \multirow{2}{*}{ Program } & \multirow{2}{*}{$\begin{array}{c}\text { Pelaksanaan } \\
\text { Program }\end{array}$} & \multirow{2}{*}{ Waktu } & \multicolumn{3}{|c|}{ Rincian Biaya } \\
\hline & & & Volume & Satuan & Jumlah \\
\hline $\mathbf{N U}$ & Pemberian & Dilaksana & & & \\
\hline Preneur: & ternak & kan pada & & & \\
\hline Program & kambing & bulan & & 900.000 & 18.000 .000 \\
\hline Pemberday & untuk & ramadhan & & & \\
\hline aan & dipelihara & $1435 \mathrm{H}$ & & & \\
\hline
\end{tabular}


Ani Mardiantari:

Peranan ZIS dalam Upaya Meningkatkan Perekonomian

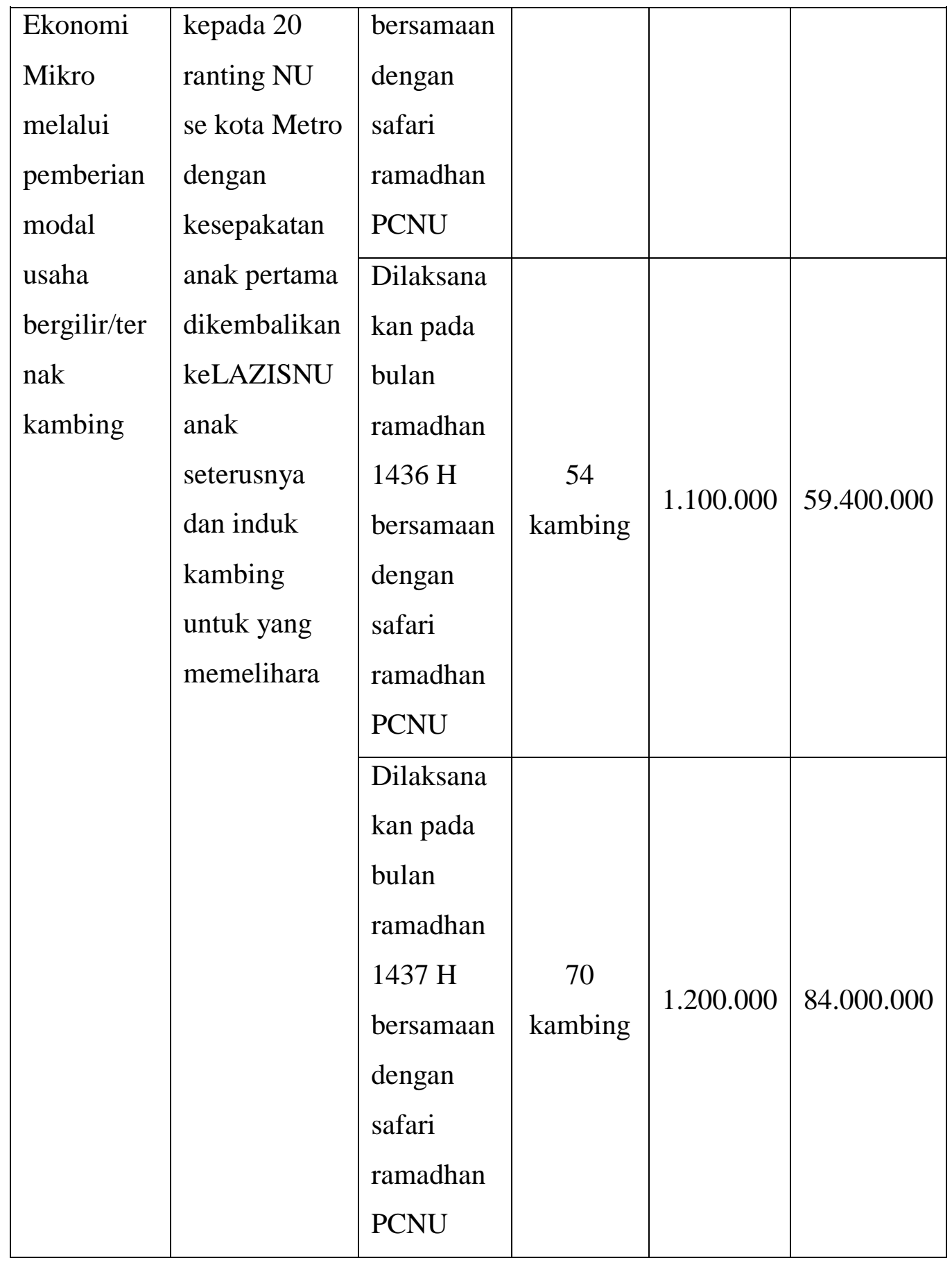

Dari tabel di atas khusus untuk program NUPreneur kambing bergilir dimulai pada tahun 2014 yang total pengumpulannya sebanyak Rp 11.300.000,dan 20 Ekor Kambing, tahun 2015 jumlah dana yang dikumpulkan meningkat menjadi Rp 12.550.000,- dan 54 ekor Kambing, 2016 pengumpulannya mengalami kenaikan pula Rp 12.700.000,- dan 75 Ekor kambing setelah itu di 
tahun 2017 pengumpulannya mengalami kenaikan seperti tahun - tahun sebelumnya namun kenaikannya dengan jumlah yang berbeda menjadi Rp 21.150.000,- dan 104 ekor Kambing. Hal ini membuktikan bahwa potensi LAZISNU Kota Metro setiap tahun menjadi baik dan butuh pengelolaan khusus agar dana zakat yang dikeluarkan oleh Muzakki bisa dikelola dengan baik. Hal ini dilakukan agar peran LAZISNU bagi peningkatan kesejahteraan masyarakat dari tahun ke tahun akan selalu mengalami peningkatan sehingga akan mengurangi tingkat kemiskinan yang ada di wilayah Metro.

Bantuan modal usaha bergulir berupa pemberian kambing ini dapat menjadi sebuah solusi yang efektif bagi para mustahiq untuk dapat meningkatkan kesejahteraan hidupnya. Sebab dengan bantuan ini masyarakat akan mendapatkan keuntungan dan ini akan memberikan motifasi kepada para mustahiq untuk berusaha keras.

Peneliti mewawancarai Bapak Mujito dari Kecamatan Metro Utara selaku mustahiq yang menerima bantuan kambing bergulir dari LAZISNU Kota Metro, beliau mengatakan:

"Bantuan ini sangat bermanfaat bagi keluarga kami, karena bantuan ini sangat membantu dan menjadi salah satu sumber pendapatan bagi kami. Bantuan ini sudah saya manfaatkan ketika anak kami mau masuk SMP karena butuh biaya besar maka kami jual anak kambing untuk biaya masuknya". ${ }^{13}$

Penerima bantuan kambing bergulir dari LAZISNU Kota Metro lainnya yaitu Bapak Miftakhul Alimin, juga menambahkan:

"Bantuan ini besar sekali manfaatnya, kalau kita merawatnya dengan telaten dan benar maka kambing-kambing ini akan cepat berkembangbiaknya. Jadi bantuan ini sangat bermanfaat sekali. Keuntungan dari pemeliharaan kambing ini bisa dipakai untuk kebutuhan lainnya. Namun menurut saya dari pihak pemberi bantuan untuk bimbingannya masih kurang karena pengalaman saya selama ini dari pihak pemberi bantuan tidak ada kunjungan lagi yang menanyakan bagaimana tentang bantuan kambing ini.",14

Tujuan dari diadakannya program ini adalah untuk melatih mustahiq agar dapat mandiri dan bertanggung jawab atas bantuan yang diperolehnya. Selain itu juga diharapkan untuk mewujudkan pemerataan pendapatan di kalangan masyarakat sehingga hal ini dapat mengurangi kemiskinan dan meningkatkan 
kesejahteraan bagi para mustahiq. Oleh sebab itu LAZISNU Kota Metro menekankan wajib bagi penerima bantuan kambing bergulir untuk mengembalikan anak pertama dari kambing tersebut dengan tujuan untuk menanamkan tanggung jawab kepada mustahiq dan agar bantuan yang dikembalikan dapat digulirkan kepada mustahiq lainnya.

Pada dasarnya konsep daripada zakat diharapkan dapat mengubah mustahiq menjadi muzakki, dengan kata lain dari miskin menjadi kaya atau berkecukupan dan kemudian pada gilirannya mampu mengeluarkan zakat. Melalui program ini diharapkan mampu mendorong mustahiq untuk terus berusaha secara bersungguh-sungguh sehingga diharapkan mampu merubah mustahiq menjadi muzakki secara bertahap.

\section{Kendala yang dihadapi oleh LAZISNU Kota Metro}

Kendala-kendala yang dihadapi oleh LAZISNU Kota Metro di antaranya adalah sebagai berikut:

1. Kurangnya kesadaran muzakki dalam mengeluarkan zakatnya di LAZISNU Kota Metro

2. Tidak adanya sanksi yang tegas dalam Undang-Undang Pengelolaan Zakat bagi muzakki yang tidak mengeluarkan zakatnya

3. Keterbatasan Dana

4. Kurangnya kepercayaan masyarakat kepada LAZISNU Kota Metro

\section{E. Upaya LAZISNU Kota Metro Menyelesaikan Kendala Yang Dihadapi}

Ketika menghadapi suatu kendala LAZISNU Kota Metro tidak tinggal diam, dalam menghadapi kendala-kendala tersebut LAZISNU Kota Metro sudah melakukan beberapa upaya untuk menyelesaikannya, diantaranya adalah:

1. Melakukan sosialisasi

2. Membentuk UPZ

3. Memberikan kemudahan kepada muzakki 


\section{PENUTUP}

Sebagai sebuah lembaga daerah nonstruktural yang diberi kewenangan untuk mengelola dan mengembangkan zakat, infak dan sedekah serta harta agama lainnya keberadaan LAZISNU Kota Metro sangat berperan positif dalam peningkatan grafik pertumbuhan ekonomi. Zakat, infak dan sedekah yang dihimpun dan disalurkan bukan hanya yang bersifat konsumtif saja,melainkan juga yang bersifat produktif. Penerapan ZIS produktif pada LAZISNU Kota Metro adalah dengan pemberian bantuan ternak bergulir dengan syarat anak pertama dari ternak tersebut dikembalikan kepada pihak LAZISNU Kota Metro untuk diberikan kepada mustahiq yang lainnya.

Dampak dari penerapan ZIS produktif pada LAZISNU Kota Metro yaitu menjadi salah satu penunjang kemakmuran masyarakat karena telah memberikan hasil yang signifikan diantaranya adalah dengan memberdayakan masyarakat dari ekonomi lemah, dapat memotivasi dan mempunyai rasa tanggung jawab khusunya bagi mustahiq untuk selalu berusaha dengan baik dan maksimal serta dapat menghasilkan finansial bagi terciptanya kesejahteraan hidup masyarakat miskin.

Saran dalam upaya mengoptimalisasi peran LAZISNU Kota Metro dalam upaya meningkatkan kesejahteraan masyarakat melalui dana zakat, infak dan sedekah, yaitu mengoptimalkan pengelolaan dan memaksimalkan pengumpulan, pendistribusian dan pendayagunaan zakat, infak dan sedekah karena jika hal ini terus ditingkatkan maka hal ini dapat menjadikan dana ZIS benar-benar berperan dalam peningkatan kesejahteraan masyarakat.

\section{Catatan Akhir}

1 "Wawancara Dengan Bapak Subandi (Ketua LAZISNU Kota Metro), Pada Tanggal 17 November 2018 Pukul 09.00 WIB,” n.d.

2 "Wawancara Dengan Bapak Subandi (Ketua LAZISNU Kota Metro), Pada Tanggal 17 November 2018 Pukul 09.00 WIB.”

3 "Wawancara Dengan Bapak Subandi (Ketua LAZISNU Kota Metro), Pada Tanggal 17 November 2018 Pukul 09.00 WIB.”

${ }^{4}$ Husaini Usman, Manajemen Teori, Praktik Dan Riset Pendidikan (BUMI AKSARA, 2013). 
5 "Wawancara Dengan Bapak Subandi (Ketua LAZISNU Kota Metro), Pada Tanggal 17 November 2018 Pukul 09.00 WIB."

${ }^{6}$ Usman, Manajemen Teori, Praktik Dan Riset Pendidikan.

7 "Wawancara Dengan Bapak Markaban Ilyas (Bendahara LAZISNU Kota Metro), Pada Tanggal 24 November 2018 Pukul 11.00 WIB," n.d.

8 "Wawancara Dengan Bapak Subandi (Ketua LAZISNU Kota Metro), Pada Tanggal 17 November 2018 Pukul 09.00 WIB."

9 "Wawancara Dengan Bapak Markaban Ilyas (Bendahara LAZISNU Kota Metro), Pada Tanggal 24 November 2018 Pukul 11.00 WIB."

10 "Wawancara Dengan Bapak Markaban Ilyas (Bendahara LAZISNU Kota Metro), Pada Tanggal 24 November 2018 Pukul 11.00 WIB."

11 "Wawancara Dengan Bapak Subandi (Ketua LAZISNU Kota Metro), Pada Tanggal 17 November 2018 Pukul 09.00 WIB."

12 "Wawancara Dengan Bapak Subandi (Ketua LAZISNU Kota Metro), Pada Tanggal 17 November 2018 Pukul 09.00 WIB."

13 “Mujito (59 Tahun), Petani, Wawancara, Metro, 08 Desember 2018," n.d.

14 "Miftakhul Alimin (50 Tahun), Buruh Harian Lepas, Wawancara, Metro, 08 Desember 2018," n.d.

\section{DAFTAR PUSTAKA}

Damayanti, Wiwik, Ita Dwilestari, and Budi Wahyono. "Dimensi Zakat Dalam Keadilan Sosial (Studi Komparasi Pemikiran Yusuf Al Qardhawi Dan Masdar Farid Mas'udi)." JURNAL MAHKAMAH: Kajian Ilmu Hukum Dan Hukum Islam 3, no. 1 (June 30, 2018): 1-28. https://doi.org/10.25217/jm.v3i1.251.

Hafidhuddin, Didin. “Panduan Praktis Tentang Zakat, Infak, Sedekah,” 1998.

Kurnia, Hikmat. "Panduan Pintar Zakat: Harta Berkah, Pahala Bertambah plus Cara Tepat Dan Mudah Menghitung Zakat,” 2008.

Mardani. "Hukum ekonomi syariah di Indonesia," 2011.

"Miftakhul Alimin (50 Tahun), Buruh Harian Lepas, Wawancara, Metro, 08 Desember 2018," n.d.

Mufraini;, M. Arief. Akutansi dan Manajemen Zakat. Prenada Media group, 2008. //library.iaimnumetrolampung.ac.id/index.php?p=show_detail\&id=22902 $\&$ keywords=akuntansi+dan+manajemen+zakat. 
Muhklisin, Ahmad. "KAJIAN HUKUM ISLAM TERHADAP DINAMIKA PELAKSANAAN ZAKAT PADI." JURNAL MAHKAMAH : Kajian Ilmu Hukum Dan Hukum Islam 1, no. 2 (December 5, 2016): 425-43.

“Mujito (59 Tahun), Petani, Wawancara, Metro, 08 Desember 2018," n.d.

Qardawi;, Yusuf. Hukum Zakat. Litera Antarnusa, 2007. //library.iaimnumetrolampung.ac.id/index.php?p=show_detail\&id=27640 \&keywords=yusuf+qardawi.

Sari, Elsi kartika. Pengantar Hukum Zakat Dan Wakaf. Grasindo, 2006.

Subandi, Subandi. "MANAJEMEN ZAKAT, INFAQ DAN SHADAKAH (ZIS) PRODUKTIF (ZIS BERBASIS KEWIRAUSAHAAN DI LAZIZNU KOTA METRO TAHUN 2015)." FIKRI: Jurnal Kajian Agama, Sosial Dan Budaya 1, no. 1 (March 3, 2017): 143-68.

SUDEWO, Eri. Manajemen Zakat: Tinggalkan 15 Tradisi, Terapkan 4 Prinsip Dasar. 2013, n.d.

Usman, Husaini. Manajemen Teori, Praktik Dan Riset Pendidikan. BUMI AKSARA, 2013.

"Wawancara Dengan Bapak Markaban Ilyas (Bendahara LAZISNU Kota Metro), Pada Tanggal 24 November 2018 Pukul 11.00 WIB," n.d.

"Wawancara Dengan Bapak Subandi (Ketua LAZISNU Kota Metro), Pada Tanggal 17 November 2018 Pukul 09.00 WIB," n.d. 